The action of water is the same as that of a poultice, only in a minor degree.

Such an explanation helps one out of the difficulty which constantly arises when we are foiled by the appearance of pusin a wound after using the utmost caution in its dressing to exclude a germ. Allow it, and then we can go even further, and say that pus, like the wort of beer, is organic tissue changed by the action of warmtb and moisture, and thus brought into a state of preparedness for fermentative changes, when the ferment alights upon it.

One is wonderfully assisted in the consideration of this subject by the recent investigations of Pasteur. What he has told us in his "Etudes sur la Bière" of the process of fermentation, and of the preliminary changes which must occur in the barley to establish germination before ever the ferment is added, affords, as he foresaw, not merely an analogy, but an identity, in the series of changes which occur when a diseased germ enters either vegetable or animal tissue. It is only in strict accordance with the mode of action of the germ on the vegetable organism, which has previously been prepared for it by the aid of warmth and moisture, if we find that the same state of preparedness is necessary in the animal organism before the germ can act upon it. Warmth and moisture are the necessary agents for the purpose here, as in the other case. The barley might lie for years surrounded by an atmosphere flled with the spores and germs of vegetable life, yet these would never work any change in it till heat and moisture had effected certain alterations. To put it in another way, the insoluble matter stored up in the seed becomes by these digested and then used up for the production of other tissue. The natural grrmination of the barley takes place when it is put below the soil, where not only heat and moisture surround it, but other necessary conditions. By the aid of these it goes through all the stages of growth until it has produced others like itself. But suppose instead of this we substitute the maltster's plan, which consists in imitating nature so far as to supply the heat and moisture, and by them setting up germination, and as soon as that has been carried to a certain extent, the heat and moisture are witbdrawn and a drying process, for the purpose of thoroughly ebecking further germination, is employed. This kiln-drying completely destroys, kills, what may be termed the germ life. After this no possible means could set it up again. The barley is so altered that it is now fitted for another form of life; it has become fitted to be the rich pabulum for the lowest form of organic life, and what is called fermentation, which is but the rapid reproduction of monad life, takes place through the germ having met with its appropriate element and feeder in the infusion of malt.

Whence comes this germ? The answer to that is, from without. The researches and experiments of Pasteur, Tyndall, and others have established this.

Without carrying the illustration of the barley an further, it may be well to allude to other forms of organic life, because exception might be taken to the barley as being a seed, the ultimate product of germination, in which are stored up reproductive forces which, in being latent, are in some way different from those of ordinary tissue, such as the leaves and stems of plants. But the only difference is this, that if you reduce any of these to dryness after their removal from the soil, it will remain unchanged for years; but you could not start them into life again, and therefore germination is not possible with them. If, however, you immerse any of them in water at a moderate temperature, in a few bours degenerative changes will take place. The albuminoid matter stored up in them is digested, in other words, is rendered soluble, and the ferment or germ, which Trofessor Tyndall finds so difficult to exclude, settling upon them, can now work a successive series of changes.

But in what does this differ from the barley? In the latter you merely start the germinal life, and at some phase of its existence destroy it-it matters not which; after that you have a state of things precisely similar to the leaf or stem.

What has now been said of vegetable life holds good of animal life. It is a higher and more complex life, but in its dissolution it obeys the same laws. The Memphian mummy prov s that human tissue can be held together unchanged for centuries if certain forces in nature be prevented from acting upon it; whilst, in the ordinary course of things, these forces at once attack it, and prepare, or rather fit it to be the very material for which certain other agencies abroad in nature have an intense affinity.

The one thought, I bave here attempted to elucidate is this: that heat and misture are the first necessary agents required to effoct changes in the albuminous matters contained in all oruanic tissue before germs or ferments can work any changr upon them; and therefore it is a chemical change after al:, for the "life proper," so to speak, of tissue is destroyed by the action of these agents, and at the same moment the arrangement of its constituents is transposed, and all this before it can be made available for the sustenance and development of otber and altogether different life forms.

$$
\text { ( } T \text { o be continued.) }
$$

\section{TREATMENT OF SCROFULOUS LYMPHATIC GLANDS BY A PAINLESS ELECTRO- LYTIC CAUSTIC.}

By C. H. GOLDING-BIRD, B.A., M.B., ASSISTANT-SURGROX TO GUT'S HOSPITAX.

(Concluded from page 565.)

ThE following cases illustrate the use of the method described in the former part of this paper.

CAse 1.-Sarah $\mathrm{P}-$, aged twelve, was under my care in Guy's Hospital for two months and a half, suffering from scrofulous enlargement of the glands in the neck in their last or suppurative stage. It was five years since the glands first commenced diccharging, and she had been under medical tre tment, but the only local remedy ordered had been poultices.

On admission, March 27 th, 1876 , the patient's neck and upper part of chest were studded with cicatrices, and beneath the lower jaw were two sinuses, each leading to a mass of enlarged glands. There was also a small superficial ulcer in the same region. The swelling beneath the jaw extended some distance down towards the sternum, and gave the child a pouting appearance. Ordered two drachms of a mixture of cod-liver oil with iron three times a day, and cold water dressings.

March 3 lst.-A piece of zinc wire about three-quarters of an inch long was thiust down each sinus into the grannlating gland substance, and there retained by strapping. Each wire passed through a shield of thick gutta percha and terminated externally in a loop, to which was fastened a piece of copper wire that had been soldered by its other extremity to a small plate of sheet silver. The latter was evenly strapped over the ulcer under the chin. The whole was enveloped in cotton-wool, and then a bandage passing under the chin and over the head made all secure. The patient was all,wed to be about the ward.

April 1st.-Apparatus removed; patient has suffered no pain. In place of two semi-protruding glands, two greywhite, curdy-looking masses are to be seen, and the surrounding tissues are bard and indurated. This grey slough is acid to test-paper, but the discharge under the silver plate is strongly alkaline. Ordered to poultice.

4th.- Slough not entirely separated, so plates reapplied as before.

$6 \mathrm{th}$.-On removing the zinc, a slough of the size and shape of a gland was found loose, and removed. There is yet more slongh to separate. The child bas suffered no pain. Apparatus reapplied.

7th.-A pparatus removed. Ordered to poultice.

8th.-More sl agh bas come away on the poultices, and some has been removed by the forceps.' This last time the zinc wire was bent in the form of a horseshoe, and beaten out so as to present a greater surface.

9 th and 10 th.-More slough continues to be discharged on the poultices.

11th.-The wounds have cleaned, and more granulating gland tissue is to be seen, so apparatus to be reapplied.

13th.-Zinc removed; the glands are converted into grey friable material, that breaks down under the forceps on trying to extract it. To poultice. 
15th.-A pparat us reapplied.

19th.-Ove sinus bas n+arly closed, the other presents a grey slough. To poultice.

On the 20 th and 25 th the apparatus was again employed, and poultices in the intervals.

28th.-One opeuing has quite healed; the other is very small, but it still leads down to a hard mass some distance below the surtace.

On May 6tb a piece of zinc wire, flattened and pointed like a spear-bead, and passed as usual through a shield of gutta-percha, was thrust into the remaining sinus for one inch and a half. The silver plate was applied as before.

8th.-Some pain and tenderness over the lower part of the face, so the zine was removed, and with it some slough, and poultices ordered.

12th.-Canstic r-applied as on the last occasion.

17th.-Removed the zinc, which was thickly coated with the slough. Ordered water-dressing.

23rd.-Caustic reapplied, and removed again on the 26th. Much slough came away at the time. Patient has com. plained of no pain at all. Some thickening still remains, deeply situated. To poultice.

June $10 \mathrm{rb}$.- The thickening that was felt on the last occasion, and thought to be glandular, is rapidly disappearing, and so is probably only inflammatory. All the slough has come away, and the wound has nearly closed. Beneath the jaw the tissues are quite supple, and no indurated glands are to be felt.

1lth.-Discharged from hospital.

Remarks-For five years this patient had suffered, and was cured in two months without any pain, and without being invalided in any way. She was constantly running about the ward or in the hospital grounds, and, excepting that it was the first case I had had-an experimental case, and therefore requiring close observation-the child might have easily been relieved as an out-patient. For the same reason the time of treatment was more extended than necessary, and the caustic was removed at far more frequent intervals than is now known to be requisite. Zine wire, of the size of ordinary enpper bell-wire, was employed, at times beaten out to present a greater surface, but the points of thin sheet zine $I$ bave already mentioned are easier prepared and in every way preferable.

CASE 2-Eliza W-, aged eighteen, was admitted under my care into Gray's Hospital in April, 1876. For eight years she had suffered from enlarged and suppurating glands in the neck. On adwission some were still discharging through sinuses, and there were many depressed cicatrices of old abscesses. At the angle of the lower jaw on the left side was a granulating gland mass that had been presenting at the opening in the skin for five months. The patient was sickly in appearance and stunted in growth, and both intellectually and functionally much behind ber years.

On April 13rh she was ordered compound iron mixture, one ounce three times a day. The zinc electrolytic caustic was applied to the gland at the angle of the jaw. The silver plate was attached to a neigbouring superficial sore. On April 15th the apparatus was removed, and two days later the slongh had separated. On the 17 th it was reapplied, and on the $19^{\prime} \mathrm{h}$ slough of the shape of a lymphatic gland was shelled out on the removal of the zinc. Some fresh enlargement of the lymphatics under the chin being now observed, and as the patient's teeth were found very decayed, she was discharged from the hospital, and ordered, when she had seen the dentist, to return as an out-patient.

In a fortnight (May 8tb) the patient again appeared. There was still an opening at the angle of the jaw, which led down to some thickening. The apparatus was once more applied, the zinc being, as on previous occasions, thrust down into the glandular swelling. On May 10 th it was removed; on the 13th the slough separated, and by the 22nd the wound had nearly closed.

'To months later, after being in the country, the patient again presented herself (July 17th). I then made this note: "There is only a scar now at the angle of the jaw; the gland under the chin has disappeared, and her general health is much improved."

I saw this patient for the last time on Jan. 29th, 1877, and then noted down: "Nothing to be seen or felt now beyond the superficial scars. From a surgical point of view the patient is quite well."

Remarks.-This was the first case I treated as an out- patient. By keeping a bandage over the apparatus the gir? was able to be about at home as usual, only coming up on certain days. Throughout she never complained of the slightest pain.

CASE 3.-Julia R-, aged sixteen, was under Mr. Cooper Forster's care in Guy's Hospital in Mar, 1876. The patient is a delicate girl, and for years has suffered from enlarged glands in the neck. Two years ago they suppurated, and for cne year continued discharging; they then healed.

On admission there was seen on the right side of the neck, near the angle of the jaw, a mass of enlarged glands the size of a large hen's egg, which projected as an unsightly tumour, the skin over which was in some parts normal, in others cicatricial and adherent. Beneath the integument, the glands, though matted somewhat together, could be in. dividually distinguished; they were freely movable en masse, and appeared to extend deeply. The glandulæ concatinatw of the same side were also slightly enlaryed.

May 13th. - The skin being sound, two punctures were made into the tumour with a bistoury, and two pieces of zinc wire beaten out and pointed were thrust in for the depth of an incb; the other connexions were made as usual, the silver lying upon a freshly blistered surface behind the ear.

17th.-A pparatus removed. To poultice.

20th.-Three glande came away. The skin has sloughed some distance round the punctures.

22nd.-Two zinc points applied as before.

28th.-Three glands have come out in the poultices. The caustic was worn till the 26 th.

29th.-Two glands have come away.

June 3rd.-Three zinc points employed as before.

6th.-Apparatus removed. The patient has complained

this time of some pain.

8th.-One large slough has come away on the poultices.

9th.-Two more glands have come aw:y.

12th.-A pparatus reapplied as on the 3rd.

16th.-Caustic removed. To poultice.

20th.-A wound remains, measuring an inch by half an inch. Ordered carbolic oil dressing.

29th.-Patient discharged. Wound nearly healed.

Remarks - On the patient's discharge the mass of glands was removed; only two or three movable ones to be felt deeply; all the visible deformity was gone. The glandulx concatinatæ still remained as at first. The disease beingat least anatomically-in its second stage, excision would have been easy and expeditious; however, the caustic did its work well and painlessly in seven weeks. This is the only case in which the skin has been destroyed; it seems to resist the caustic, as a rule, very well. The patient com. plained of pain once (June 6th); there was nothing seen to account for it, for it was not on the occasion of the destruc tion of the integument.

The three cases that have been given will suffice to show the mode of working and the detail of the treatment. The remaining cases, all under my care as out-patients, may bo given in outline.

CASE 4.-Frank D-, aged twenty-four, clerk. First seen in 1873 with an enlarged lymphatic gland in submaxillary region; he was ordered tonics. Christmas, 1875 , the gland inflamed, suppurated, and a granulating mass protruding through the skin resulted. For the next six months the red oxide of mercury ointment was applied, as well as iodoform, but with no real benefit. Having to be at his work with his head constantly tied up, he was anxious for something to be done. On May 8th a flattened zino wire point, bent as a horseshoe, was thrust into the gland, the silver being applied to a recently-blistered surface close by. On the fourth day the apparatus was removed; the same evening the gland came away on the ponltice. On June 12th (one month) the patient returned quite well; one other small gland was felt lying deeply, but was not interfered with, as it caused no disfigurement.

Remarks. - This patient was about as usual. He never complained of any pain.

CASE 5.-William W-, aged thirteen, from childhood had suffered from enlarged glands, and for four months had had one semi-protruding through the skin beneath the chin. One application of the caustic was made on Hlay 24th, 1876. On the 29th the apparatus was removed, and two weeks after (June 12th) only a small superficial sore was left. I have not seen the lad since, and so I suppose be 
remains vell. He never suffered the slightest pain or inconvenience.

CASE 6.-Jihn J-, aged ten, an out-patient at Guy's Hosvital. F.r two years has had suppurating glands about the neck, and he now presents many scars of old abscesses. Behind the sterno-mastoid on the left side of the neck, and beneath the chin, there were in all five open sores, situated either on bard bases and presenting a granulating surface, or else small and leading distinctly down to gland-tissue. For four months in all this patient was under observationJuly to Novemher, 1876, - but in September he did not appear. During this period the electrolytic caustic was employed seven times-viz., July 18th and 24th; three times during August by my dresser, in my absence; and again by myself on Oct. 27 th and Nov. 29 th. On this last occasion the motber of the child removed the apparatus after it had been on only two days, as he complained of pain. On Dec. 4th, when I examined the patient, I found about half an inch of skin destroyed around the zine point. He was last seen on Jan. 22nd, 1877, and was then per. fectly well.

CASE 7.-Thomas J_- aged nine, brother to Case 6, was an out-patient under my care on two separate occasionsviz, in October, 1876, and January, 1877. He had been very much in the same condition as his brother, but now presented only two sores; one quite small, under the chin, over an enlarged gland, and another, linear in shape, on the cheek, between two and three inches long, reaching from the ear to the angle of the jaw. Its edges and base were hard, and the mother stated it had been discharging the same seropurulent material for years. On the Oct. 27 th I applied the caustic to this linear sore. The form of zinc employed (vide woodcut, p. 565) was that of a saw with coarse teeth, thrust through a shield of gutta percha. The teeth entered the granulating surface, and were thrust to the required depth. The silver plate was fastened over the small sore beneath the chin. The patient only complained of the prick the zinc caused when being fixed in its position.

0ct. 30th.-Apparatus removed, and with the zinc some slough came away, leaving a clean excavated surface. Poultices were ordered. No pain has been suffered.

In a month there was nothing but a cicatrix left. Some time later it broke down in part, but healed under simple dressings.

In January, 1877, the gland under the chin was completely destroyed in one application of the zinc. It was retained for five days. In a fortnight the patient was quite well.

Remarls - The saw-like piece of sheet zinc that was employed to suit the shape of the ulcer was toothed so as to allow of its penetration. Where a large surface has to he destroyed a flat piece of zinc would be employed, but for this class of cases the form of zinc points shown in the woodcut (p. 565) will answer all purposes. After the destruction of the gland under the chin, the piece of skin which covered it over hung down as a flap, having been unaffected by the caustic. It was strapped up into its place again, and there united.

CASE 8-Eliza $\mathrm{S}$-, aged eighteen, was in Guy's Hospital under my care for a short time in December, 1876; she then became an out-patient, and is still under observation. She is the subject of congenital syphilis, and presents as bad an appearance, from the presence of protruding glands in the neck, as I have yet had to deal with. There are several openings, but the two principal ones are connected with enlargement of the upper glandulæ concatinat $\infty$ on both sides. Fich mass stands out prominently, that on the right side being the worse.

Dec. 15th.-Ordered a mixture containing perchloride of mercury. The caustic was applied to the glands on the right side: the zinc was cut as a long horseshoe, and thrust for some depth into the substance of the swelling. The other connexions were made as usual.

From this time to January 11 th, 1877 , the canstic was enployed five times, a large amount of slongh coming away after each application. Poultices were ordered in the intervals. The zinc was retained, on an average, four days each time. The girl now attended as an out-patient, and by the end of January the sinus had closed, and, though some thickening remained, it has been gradually diminishing since then. She has suffered no pain.

The gland-mass on the left side was attacked on Feb. 7th in the same way; it was a red fungating mass of granulation tissue the size of a hen's egg. It is rapidly diminish. ing under the treatment and without pain, though to-day (March 9th) the patient has complained of a constant aching pain for the last four days, during which the apparatus has been worn. There is no destruction of the skin to account for it.

The great advantage that the electrolytic caustic offers over other caustics, is its painlessness, while it retains in common with the ordinary chloride of zine "arrows" a great adaptability to deep situations. The Vienna paste, used in Germany for the destruction of scrofulous glands, is not so painful as the chloride of zinc, but it soon deliquesces, and can only be applied superficially.

The principle of the electrolytic treatment is old, even if its application in the method I have described in such cases as those narrated is new. About 1848 it was suggested by the late Dr. Golding Bird in this country as a painless method of forming issues, under the name of the "electric moxa,"1 and was once employed by Mr. Bransby Cooper as an escharotic in a case of carcinoma mammæ. Cicatrisation is said to have resulted from its employment, and the pain that the patient was enduring to have been relieved.

\section{A. aflirror $^{2}$}

\section{HOSPITAL PRACTICE,}

\section{BRITISH AND FOREIGN.}

Nalla autem est alia pro certo noscendi via, nisi quamplurimas et morbornm et dissectionum historias, tum aliorum, tam proprias collectas habere, et inter se comparare.-Hongagni De Sed. et Caus. Morb., lib. iv. Procomium.

\section{WESTMINSTER HOSPITAL.}

\section{LOOSENING OF THE PELVIC SYMPHYSES.}

(Under the care of Dr. Basham.)

There can be no doubt from the history of this case that there was loosening of the pelvic symphyses, a condition which, though somewhat rare, is said to occur in pregnancy, and to be physiological, but which becomes pathological should it continue after an otherwise complete recovery. There is, it is believed, generally a little softening of of the pelvic joints and relaxation of the ligaments during pregnancy, and especially of the symphysis pubis, and probably this softening allows of a very little enlargement of the pelvic brim during labour, but this must be very slight. If this loosening exceeds a certain degree, walking becomes almost impossible. The only rational trea tment is to support the pelvis mechanically so as to artificially consolidate it, as it were.

For the following notes we are indebted to Mr. Howard Cane, house-physician.

Isabella $\mathrm{S}-$, aged thirty-four, was admittad on Sept. 7th, 1876. She was carried into the ward, as she was quite unable to walk. She gave the following account:She had her first child at eighteen years of age, and was delivered with the aid of forceps, the child being stillborn. Subsequently, at intervals of from two years and a half to three years, she had three more children, all of whom were born alive, and there was nothing abnormal at their birth. She then became pregnant for a fifth time, and during this pregnancy she noticed that she bad a slight difficulty in walking, the gait being snmewhat waddling; otherwise she enjoyed perfect health. She went the full period, and was delivered of a still-born child. Beyond the labour being somewhat tedious and difisult, there was nothing abnormal, nor was the child's head in any of the labours very large. After delivery she complained of feeling very weak, much more so than after the previous labours, and also stated that she experienced a great difficulty in getting out of bed, so much so that she remained confined to bed for six weeks. She then left

1 Lectures on Electrieity and Galranism, by Golding Bird, M.D., F R.S. 